\title{
Corrigendum: The Influence of Task-Irrelevant Flankers Depends on the Composition of Emotion Categories
}

\author{
Barbara Schulte Holthausen ${ }^{1,2 *}$, Christina Regenbogen ${ }^{1,2,3}$, Bruce I. Turetsky ${ }^{4}$, \\ Frank Schneider $^{1,2}$ and Ute Habel ${ }^{1,2}$ \\ 'Department of Psychiatry, Psychotherapy and Psychosomatics, Medical Faculty, RWTH Aachen University, Aachen, \\ Germany, ${ }^{2}$ JARA-BRAIN Institute 1: Structure Function Relationship, Jülich, Germany, ${ }^{3}$ Department of Clinical Neuroscience, \\ Karolinska Institutet, Stockholm, Sweden, ${ }^{4}$ Department of Psychiatry, University of Pennsylvania, Philadelphia, PA, USA
}

Keywords: threat superiority, distractor, congruency, gender differences, emotional face processing, flanker, stimulus onset asynchrony

\section{A corrigendum on}

The Influence of Task-Irrelevant Flankers Depends on the Composition of Emotion Categories by Schulte Holthausen, B., Regenbogen, C., Turetsky, B. I., Schneider, F., and Habel, U. (2016). Front. Psychol. 7:712. doi: 10.3389/fpsyg.2016.00712

\section{OPEN ACCESS}

Edited and reviewed by: Marina A. Pavlova Eberhard Karls University of Tübingen

Germany

*Correspondence:

Barbara Schulte Holthausen baschulte@ukaachen.de

Specialty section: This article was submitted to

Emotion Science, a section of the journal Frontiers in Psychology

Received: 13 June 2016 Accepted: 23 June 2016 Published: 20 July 2016

Citation:

Schulte Holthausen B, Regenbogen C, Turetsky BI, Schneider F and Habel U (2016)

Corrigendum: The Influence of Task-Irrelevant Flankers Depends on the Composition of Emotion Categories. Front. Psychol. 7:1032. doi: 10.3389/fpsyg.2016.01032
Due to an oversight, in the original article, there was a mistake in the Author Contributions statement and CR and UH were accidentally credited with writing the paper. The corrected Author Contributions statement should read:

$\mathrm{BSH}, \mathrm{CR}, \mathrm{UH}, \mathrm{FS}$, and $\mathrm{BT}$ designed the research, $\mathrm{BSH}$ performed the research, $\mathrm{BSH}$ and $\mathrm{CR}$ analyzed the data, BSH interpreted the data and wrote the paper. All authors corrected the manuscript and gave final approval of the version to be published.

Furthermore, there was an error in affiliation 2 which was mistakenly published as JARA-BRAIN Institute 1: Structure Function Relationship, RWTH Aachen University, Aachen, Germany

The correct version is

JARA-BRAIN Institute 1: Structure Function Relationship, Jülich, Germany. The authors apologize for the oversights. These errors do not change the scientific conclusions of the article in any way.

\section{FUNDING}

This work was supported by the International Research Training Group (IRTG 1328) of the German Research Foundation (DFG). CR was supported by a post-doctoral fellowship of the German Academic Exchange Service (DAAD).

Conflict of Interest Statement: The authors declare that the research was conducted in the absence of any commercial or financial relationships that could be construed as a potential conflict of interest.

Copyright (C) 2016 Schulte Holthausen, Regenbogen, Turetsky, Schneider and Habel. This is an open-access article distributed under the terms of the Creative Commons Attribution License (CC BY). The use, distribution or reproduction in other forums is permitted, provided the original author(s) or licensor are credited and that the original publication in this journal is cited, in accordance with accepted academic practice. No use, distribution or reproduction is permitted which does not comply with these terms. 